\title{
Molecular and Symptom Analysis Reveal the Presence of New Phytoplasmas Associated with Sugarcane Grassy Shoot Disease in India
}

\author{
Kanchan Nasare and Amit Yadav, Molecular Biology and Genetic Engineering Laboratory, Vasantdada Sugar Insti- \\ tute, Manjari (Bk), Pune-412307, India; Anil K. Singh, Plant Transformation Group, International Centre for Ge- \\ netic Engineering and Biotechnology, Aruna Asaf Ali Marg, New Delhi-110067, India; K. B. Shivasharanappa and \\ Y. S. Nerkar, Molecular Biology and Genetic Engineering Laboratory, Vasantdada Sugar Institute, Manjari (Bk), \\ Pune-412307, India; and V. S. Reddy, Plant Transformation Group, International Centre for Genetic Engineering and \\ Biotechnology, Aruna Asaf Ali Marg, New Delhi-110067, India
}

\begin{abstract}
Nasare, K., Yadav, A., Singh, A. K., Shivasharanappa, K. B., Nerkar, Y. S., and Reddy, V. S. 2007. Molecular and symptom analysis reveal the presence of new phytoplasmas associated with sugarcane grassy shoot disease in India. Plant Dis. 91:1413-1418.

A total of 240 sugarcane (Saccharum officinarum) plants showing phenotypic symptoms of sugarcane grassy shoot (SCGS) disease were collected from three states of India, Maharashtra, Karnataka, and Uttar Pradesh. Phytoplasmas were detected in all symptomatic samples by the polymerase chain reaction (PCR) amplification of phytoplasma-specific 16S rRNA gene and 16S-23S rRNA spacer region (SR) sequences. No amplification was observed when DNA from asymptomatic plant samples was used as a template. Sixteen samples were selected on the basis of phenotypic symptoms and geographic location, and cloning and sequencing of the 16S rRNA and spacer regions were performed. Multiple sequence alignments of the 16S rRNA sequences revealed that they share very high sequence similarity with phytoplasmas of rice yellow dwarf, 16SrXI. However, the 16S-23S rRNA SR sequence analysis revealed that while the majority of phytoplasmas shared very high $(>99 \%)$ sequence similarity with previously reported sugarcane phytoplasmas, two of them, namely BV2 (DQ380342) and VD7 (DQ380343), shared relatively low sequence similarity (79 and $84 \%$, respectively). Therefore, these two phytoplasmas may be previously unreported ones that cause significant yield losses in sugarcane in India.
\end{abstract}

Phytoplasmas of sugarcane (Saccharum officinarum L.) are reported to be associated with three major diseases: sugarcane white leaf (SCWL), sugarcane grassy shoot (SCGS), and sugarcane yellow leaf (SCYL). In many parts of Asia, SCGS and SCWL diseases are becoming a major threat to sugarcane cultivation. SCGS and SCWL are characterized by white leaves with complete loss of chlorophyll and profuse tillering, giving the plant a grassy appearance (3). In India, SCGS phytoplasmas are spreading at an alarming rate, adversely affecting yield of the sugarcane crop. Sugarcane is a vegetatively propagated crop, and therefore phytoplasmas can be transmitted via propagation material, although phytoplasmas are also

Corresponding author: V. S. Reddy

E-mail: vsreddy@icgeb.res.in

The first three authors contributed equally to this manuscript.

* The $\boldsymbol{e}$-Xtra logo stands for "electronic extra" and indicates that Figure 1 appears in color in the online edition.

Accepted for publication 23 May 2007.

doi:10.1094/PDIS-91-11-1413

(C) 2007 The American Phytopathological Society transmitted by phloem-feeding leafhopper vectors $(22,24,28,29)$. The SCGS and SCWL phytoplasmas are closely related to phytoplasmas associated with rice yellow dwarf (RYD) disease, annual bluegrass white leaf (ABGWL), bermuda grass white leaf (BGWL), and brachiaria grass white leaf (BraWL) (8,11). SCGS and SCWL phytoplasmas have been classified under the 16SrXI-B subgroup of the rice yellow dwarf (RYD) group (16SrXI) $(8,13)$.

Extensive field surveys in three major sugarcane growing states of India, namely Maharashtra, Karnataka, and Uttar Pradesh, revealed that phytoplasma infection in sugarcane exhibits different phenotypic symptoms. These observations led to speculation that there might be more than one phytoplasma infecting sugarcane crops in India and prompted us to determine if there was genetic variation in the phytoplasma. The goal of this study was to isolate, clone, and sequence the $16 \mathrm{~S}$ rRNA gene and the $16 \mathrm{~S}-23 \mathrm{~S}$ spacer region (SR) from sugarcane plants from different regions of India showing phytoplasma-like symptoms.

\section{MATERIALS AND METHODS}

Collection of plant material. Sugarcane (S. officinarum) plant samples exhibiting at least one of the following symp- toms - creamy leaves, grassy shoot with white leaves, stunted plants with yellow leaves, and white leaf in the whorl of green leaves,-were collected from Maharashtra, Karnataka, and Uttar Pradesh states during July 2003 to December 2005. From each location, three to four samples were collected. Corresponding asymptomatic samples were also collected.

DNA extraction and polymerase chain reaction (PCR) amplification. Total DNA from leaves of healthy and infected sugarcane plants was extracted by the method of Ahrens and Seemüller (1). Concentration of DNA was estimated spectrophotometrically. DNA extracted from symptomatic sugarcane plants was used as template for PCR, while DNA extracted from corresponding asymptomatic plants was used as negative control. The 16S rRNA gene was PCR amplified using the SN910601 (GTTTGATCCTGGCTCAGGATT) and SN910502 (AACCCCGAGAACGTATT CACC) primers (16). The 16S-23S rRNA SR was PCR amplified using P3 (GGA TGGATCACCTCCTT) and P7 (CGTCCT TCATCGGCTCTT) primers (23). The PCR reaction was performed with $1 \times$ PCR buffer (Fermentas), $1.25 \mathrm{mM} \mathrm{MgCl} 2,50 \mathrm{ng}$ template DNA, $0.2 \mathrm{mM}$ of each dATP, dGTP, dTTP, and dCTP, $0.1 \mu \mathrm{M}$ of each primer, and $1 \mathrm{U}$ of Taq DNA polymerase (Fermentas) in a final reaction volume of $50 \mu \mathrm{l}$. The PCR reaction was carried out in a PTC-100 thermocycler (MJ Research) for 35 cycles comprising denaturation at $94^{\circ} \mathrm{C}$ for $30 \mathrm{~s}$; annealing at $55^{\circ} \mathrm{C}(16 \mathrm{~S}$ rRNA gene) or $57^{\circ} \mathrm{C}(16 \mathrm{~S}-23 \mathrm{~S}$ rRNA SR) for $45 \mathrm{~s}$; extension at $72^{\circ} \mathrm{C}$ for $90 \mathrm{~s}(16 \mathrm{~S}$ rRNA gene) or $60 \mathrm{~s}$ (16S-23S rRNA SR); and final extension at $72^{\circ} \mathrm{C}$ for $5 \mathrm{~min}$. The reaction mixture was electrophoresed in $1 \%$ agarose gel, and the PCR products were visualized by UV transillumination after staining with ethidium bromide. Restriction fragment length polymorphism (RFLP) analysis was performed on the PCR amplified 16S rDNA fragment using HpaII, Sau3AI, TaqI, TasI, and TauI restriction enzymes according to the manufacturer's (New England BioLabs) instructions.

Cloning and sequencing. DNA fragments of approximately $1.3 \mathrm{~kb}$ (16S rRNA 
gene) and $0.32 \mathrm{~kb}$ (16S-23S rRNA SR) were purified using QIAquick gel extraction kit (QIAGEN) and ligated to pGEM-T vector according to the manufacturer's instructions (Promega Corp.). The recombinant plasmid was used to transform Escherichia coli strain DH5 $\propto$. Plasmid DNA from individual clones was extracted with a Miniprep kit (QIAGEN) and checked for the presence of the insert by digesting the plasmid DNA with NotI and EcoRI (New England BioLabs) (data not shown). The inserts were sequenced from both directions using universal SP6 or T7 primers by the standard procedure (19).

Phylogenetic analysis. The sequences of 16S rRNA gene and 16S-23S rRNA SR from the present study were deposited in NCBI GenBank, and the accession numbers are given in Table 1. BLAST (Basic Local Alignment Search Tool) search (2) for 16S rRNA gene and 16S-23S rRNA SR sequences was performed to identify closely related nucleotide sequences available in the database (http://www.ncbi.nlm. nih.gov).
The nucleotide sequences were aligned using ClustalW program with MacVector 9.0 software. The genetic distances and similarities were calculated using the $\mathrm{Ki}$ mura 2-parameter. The phylogenetic trees were constructed using neighbor-joining by MEGA-3.1 software (12) with 1,000 bootstrap replications.

\section{RESULTS}

Disease symptoms and PCR amplification. The survey of various fields showed that grassy shoot with chlorotic or creamy white leaves was the most prevalent symptom of phytoplasma infection. All the sugarcane plant samples that exhibited one or more of the four major symptom types-cream-colored leaves, grassy shoots with white leaves, stunted plants with yellow leaves, and white leaves in a whorl of green leaves (Fig. 1) -were positive for PCR amplification of phytoplasma-specific DNA products of 1.3 and $0.32 \mathrm{~kb}$ in length representing $16 \mathrm{~S}$ rRNA gene and 16S-23S rRNA SR, respectively (data not shown). A total of 240 samples (including 42 that were asymptomatic), which were collected from three different states of India, were analyzed. No PCR amplification was observed with either set of primers when DNA from the asymptomatic samples collected from the same fields was used as template.

In an attempt to detect the polymorphism in the 16S rDNA, the PCR products were subjected to RFLP analysis. However, no significant polymorphism was detected using five restriction enzymes (HpaII, Sau3AI, TaqI, TasI, and TauI, data not shown).

Analysis of 16S rRNA gene sequences. Partial sequence $(1,183 \mathrm{bp})$ of $16 \mathrm{~S}$ rRNA gene was determined for the selected phytoplasmas listed in Table 1. The multiple sequence alignment revealed that the phytoplasmas collected from different districts as well as from a single district, although producing different symptoms, shared a very high $(>99 \%)$ sequence identity. BLAST searches for the 16S rRNA gene sequences reported in this paper (DQ459438， DQ459439， AM261829.

Table 1. Predominant symptoms of the phytoplasma-infected plants collected, their location of collection, variety of host plant, and accession numbers of the $16 \mathrm{~S}-23 \mathrm{~S}$ rRNA spacer region (SR) and 16S rRNA gene sequences reported in the present study

\begin{tabular}{|c|c|c|c|c|c|c|}
\hline \multirow[b]{2}{*}{ S. no. } & \multirow[b]{2}{*}{ Isolate } & \multirow[b]{2}{*}{ Symptoms } & \multirow[b]{2}{*}{ State } & \multirow{2}{*}{$\begin{array}{l}\text { Variety of } \\
\text { host plant }\end{array}$} & \multicolumn{2}{|c|}{ Accession no. } \\
\hline & & & & & 16S-23S rRNA SR & 16S rRNA \\
\hline 1 & NS1 & Cream colored leaves & Karnataka & Co 86032 & DQ380336 & DQ459438 \\
\hline 2 & NS5 & Grassy shoot with white leaves & Karnataka & CoC 671 & DQ380337 & \\
\hline 3 & ND1 & Stunted plants with yellow leaves & Karnataka & CoC 671 & DQ380338 & AM269744 \\
\hline 4 & ND7 & White leaf in the whorl of green leaves & Karnataka & Co 94012 & DQ380339 & AM269745 \\
\hline 5 & VG4 & Grassy shoot with white leaves & Maharashtra & Co 86032 & DQ380340 & AM269746 \\
\hline 6 & GD3 & Grassy shoot with white leaves & Maharashtra & Co 94012 & DQ380341 & AM269747 \\
\hline 7 & BV2 & Grassy shoot with white leaves & Maharashtra & Co 86032 & DQ380342 & DQ459439 \\
\hline 8 & VD7 & Grassy shoot with white leaves & Maharashtra & Co 92004 & DQ380343 & AM261831 \\
\hline 9 & DR2 & Grassy shoot with white leaves & Maharashtra & Co 86032 & DQ380344 & AM269748 \\
\hline 10 & SV3 & Grassy shoot with white leaves & Maharashtra & Co 86032 & DQ380345 & \\
\hline 11 & BO1 & Grassy shoot with white leaves & Maharashtra & CoSi 98071 & AM269739 & AM266588 \\
\hline 12 & MA4 & Stunted plants with yellow leaves & Maharashtra & $\mathrm{CoC} 671$ & & AM269749 \\
\hline 13 & SV1 & White leaf in the whorl of green leaves & Maharashtra & Co 94012 & AM261742 & AM261830 \\
\hline 14 & PW12 & Grassy shoot with white leaves & Uttar Pradesh & CoC 671 & AM261833 & AM269751 \\
\hline 15 & CM1 & White leaf in the whorl of green leaves & Uttar Pradesh & $\operatorname{CoS} 675$ & AM269740 & AM261829 \\
\hline 16 & CM6 & White leaf in the whorl of green leaves & Uttar Pradesh & $\operatorname{CoS} 8436$ & AM269741 & AM269750 \\
\hline
\end{tabular}
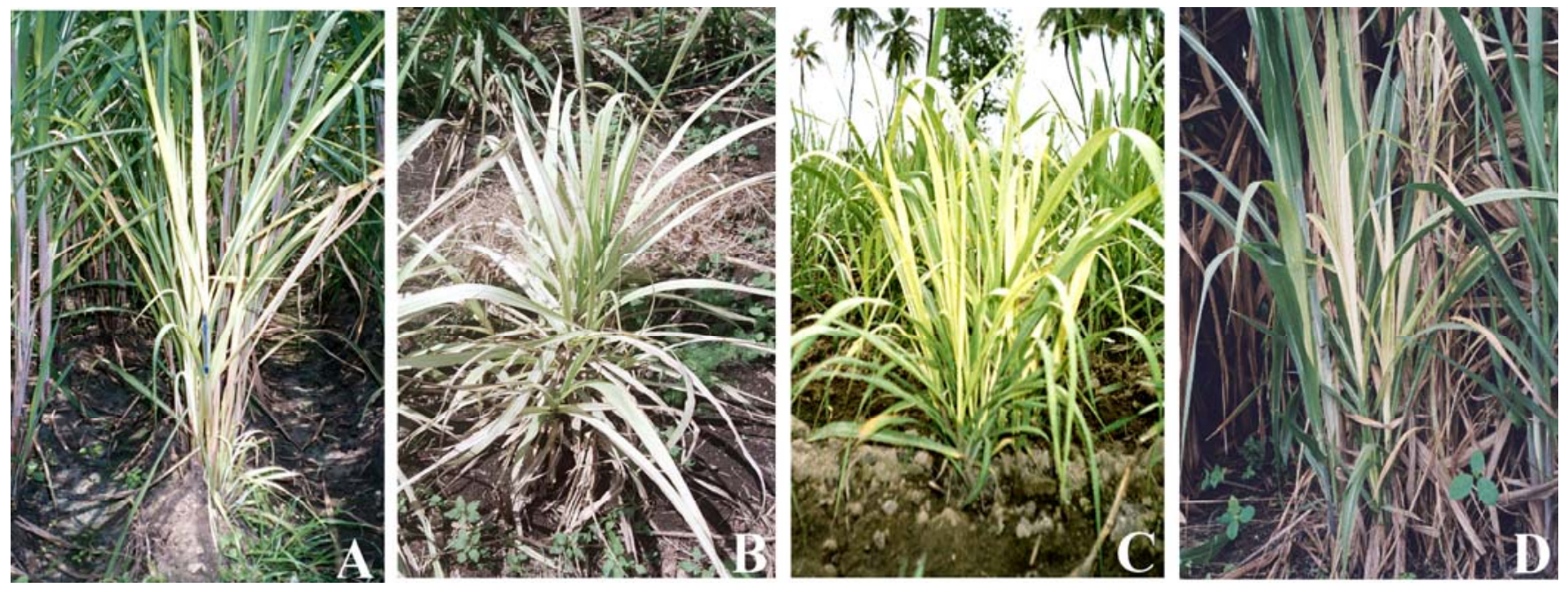

Fig. 1. Different symptoms of sugarcane grassy shoot disease: A, cream colored leaves; B, grassy shoot with white leaves; C, grassy shoot with yellow leaves; $\mathbf{D}$, white leaf in the whorl of green leaves. 
AM261830, and AM261831) indicated 99\% sequence identity with SCWL (AB052874) and Mollicutes from S. officinarum (X76432), 98\% with sorghum grassy shoot (SGS) phytoplasma (AF509325) and BGWL phytoplasma (AF248961), and 97\% with RYD phytoplasma (D12581). This confirmed that the phytoplasmas tested in this study belong to RYD 16S-group of 'Candidatus phytoplasma'. The sequence identity among the $16 \mathrm{~S}$ rRNA gene sequences reported in this paper was more than $99 \%$.

Besides this, the SCGS and SCWL shared one signature sequence, 5'-TTA-3' (positions 520-522), and three single- nucleotide alterations unique for the group: ' $\mathrm{C}$ ' at position 119, ' $\mathrm{C}$ ' at 1018 , and ' $\mathrm{T}$ ' at 1172. These sequence alterations clearly distinguish the SCGS and SCWL phytoplasmas from other phytoplasmas. Importantly, the signature sequences that are unique to members of the RYD group, such as 5'-AACACTG-3' and 5'-GCAA-3'

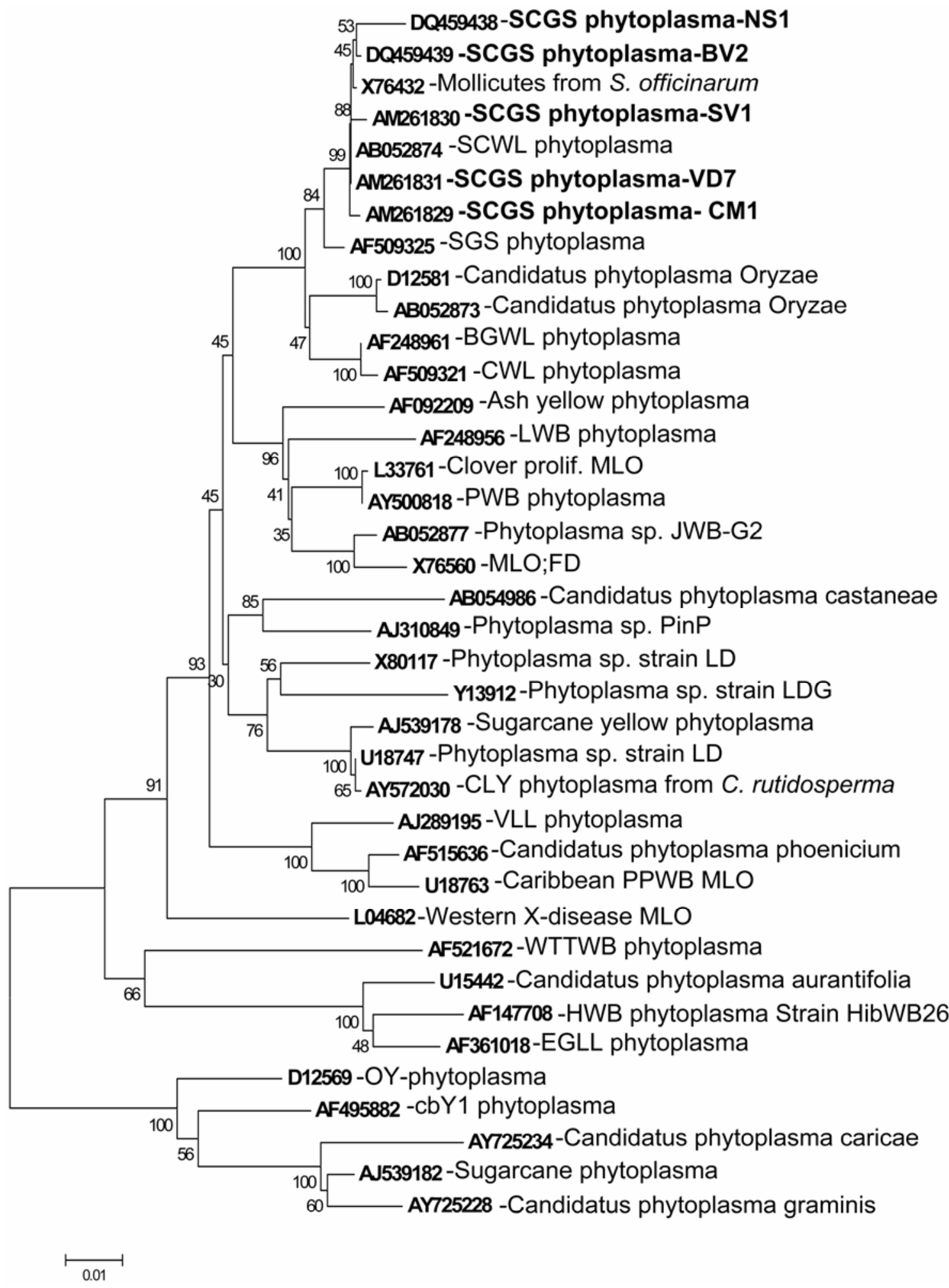

Fig. 2. Phylogenetic tree constructed by neighbor-joining method, comparing the $16 \mathrm{~S}$ rRNA gene sequences of sugarcane phytoplasma with those of other related phytoplasmas from GenBank. 16S rRNA gene sequences of phytoplasmas determined in this study are in bold. Bar represents phylogenetic distance of $1 \%$. Numbers on branches are confidence percentage obtained from 1,000 bootstrap replicates. 
(13), are also present in the AM261830, SV1; AM261829, CM1; AM261831, VD7; DQ459438, NS1; and DQ459439, BV2 phytoplasmas, reported in our samples.

To study the phylogenetic relationship of our phytoplasmas to SCGS, SCWL, and other RYD 16S-group phytoplasmas, partial $16 \mathrm{~S}$ rRNA gene sequences $(1,183 \mathrm{bp})$ of 38 phytoplasmas were aligned using ClustalW. A phylogenetic tree, constructed by neighbor-joining method with 1,000 bootstrap replications, is presented in Figure 2. All the SCGS, SCWL, and SGS formed a stable phylogenetic subcluster judged by branch length and bootstrap values of $100 \%$ in RYD 16S-group.

To rule out the possibility of amplification of the host plastid 16S rRNA gene in PCR, we performed a direct comparison of $16 \mathrm{~S}$ rRNA gene sequences of sugarcane plastome and SCGS phytoplasma. The results showed a significant difference between the two 16S rRNA gene sequences, indicating that the cloned $16 \mathrm{~S}$ rRNA gene represents the SCGS phytoplasma, not the host plant chloroplast genome.

Analysis of 16S-23S rRNA SR. Multiple sequence alignment of 16S-23S rRNA SR sequences, listed in Table 1, indicated that $16 \mathrm{~S}-23 \mathrm{~S}$ rRNA SR of all phytoplasmas were almost identical (315 bp) except for those of BV2 and VD7 (312 bp). For further analysis, 16S-23S rRNA SR sequence of NS1 isolate was taken as a representative for all the similar sequences. The NS1 (DQ380336) shared 79 and 84\% sequence identity with those of BV2 (DQ380342) and VD7 (DQ380343), respectively (Fig. 3). The BV2 and VD7 shared $83 \%$ sequence identity with each other. There was no correlation between phenotypic symptoms and SR sequence variations. For example, NS1, NS5, ND1, ND7, and SV3 exhibited different phenotypic symptoms, but had identical $16 \mathrm{~S}-23 \mathrm{~S}$ rRNA SR sequences. On the contrary, BV2 and VD7 showed similar phenotypic symptoms with those of NS5, VG4, GD3, DR2, SV3, and PW12, but represented sequence variation in $16 \mathrm{~S}-23 \mathrm{~S}$ rRNA SR.

The 16S-23S rRNA SR sequences were aligned with previously reported sequences in the database. The results showed that NS1 (DQ380336) shared 99\% sequence identity with SCGS (AB243298 and AM085763) from India and with SCWL (AF037595) from the United States. It also showed 98\% sequence identity with SCGS (AM085764) from India and SCWL (AY139874) reported from Taiwan. In the phylogenetic analysis (Fig. 4), NS1 (DQ380336), the SCGS phytoplasmas (AB243298, AM085763, and AM085764) from India, and SCWL reported from Taiwan (AY139874) and the United States (AF037595) grouped together with a bootstrap value of 92 . In contrast, BV2 (DQ380342) and VD7 (DQ380343) diverged from the other phytoplasmas and grouped together with a bootstrap value of $89 \%$. The long branching supports recent divergence of BV2 and VD7, suggesting that these phytoplasmas might be new diverging strains from the more prevalent strains represented by NS1 isolate.

\section{DISCUSSION}

Phytoplasma diseases of sugarcane (SCGS and SCWL) have been reported to cause substantial losses in the sugarcane crop all over Asia $(4-6,18,20,27)$. The chance of their transmission to other geographical regions seems to be high, given the large phytoplasma reservoir already revealed, the propensity of new phytoplasma strains to evolve (14), and the ability of leafhoppers, the most common insect vectors of phytoplasma, to migrate long distances $(25,26)$ and switch to new host plants (17). In the present study, 198 sugarcane plant samples exhibiting different symptoms tested positive for phytoplasma through PCR amplification of 16S rRNA gene and 16S-23S rRNA SR using primers specific for phytoplasmas. The presence of various symptoms in phytoplasma-infected plants led to the hypothesis that multiple strains of sugarcane phytoplasma were infecting the sugarcane crop in India. If multiple strains were present, identification and characterization of the strains in particular host plant species would be needed so that effective and early diagnostic methods, based on genetic heterogeneity, could be developed. In view of reports that some ash yellows phytoplasmas are more aggressive and can cause serious damage to less tolerant Fraxinus species (21), it is important determine whether any of the newly identified sugarcane phytoplasmas show differential aggressiveness in causing grassy shoot disease and yield losses.

A BLAST search for the 16S rRNA gene sequences reported in this paper showed that they shared more than $99 \%$ sequence identity among themselves and 97 to $99 \%$ identity with those of other phytoplasmas in the RYD 16S-group. This confirmed

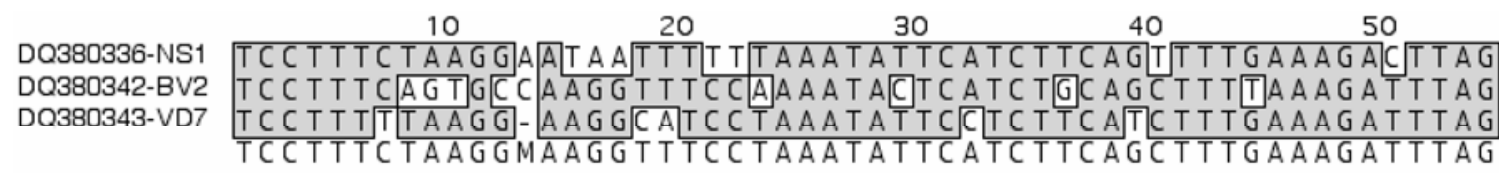

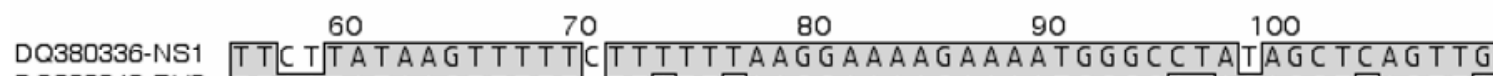
D0380342-BV2 TTAATATAAGTTTTTGTT AT TDAAGGAAAAGAAAATGGGCA-A GAG C T GA GT TA DQ380343-VD7 TTAATATAAGTTTTTTTTTTTAAGGAAAAGAAAATGGGCC- AGAGCTCAAAAG TTAATATAAGTTTTTB TTTTTAAGGAAAAGAAAATGGGCCTAGAGCTCAGTTG

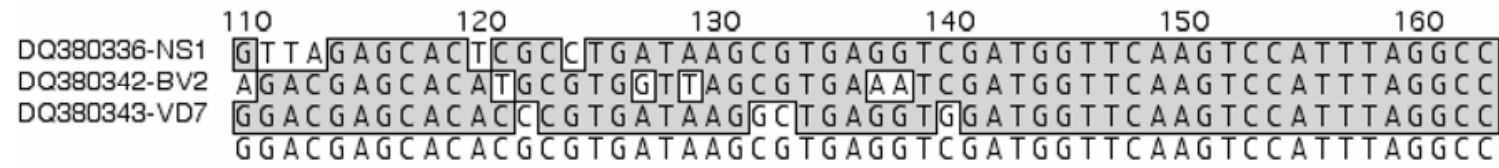

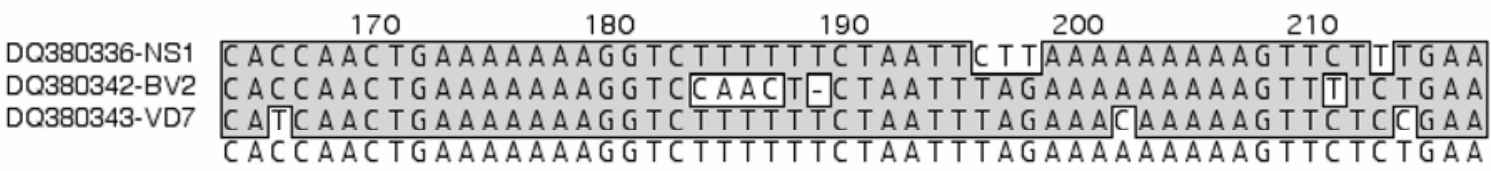

220

230

240

250

260

270

DQ380336-NS1 DQ380342-BV2 DQ380343-VD7

AAG TAGATAAACAAAG TATT TTTTTTAAAAATCAAAG

AAAA GAAAACAAAG TAGAAT TA-AAAAATCAAAG

AAAAAG TAAACAAAGTAGATTTA]- AAAAATCAAAG]

AAAAAGATAAACAAAGTAGATTTATAAAAATCAAAG

Fig. 3. Multiple sequence alignment of 16S-23S rRNA spacer region sequences of sugarcane grassy shoot (SCGS) phytoplasmas NS1, BV2, and VD7 by ClustalW. 
that the present SCGS phytoplasmas belong to RYD 16S-group of 'Candidatus phytoplasma'. Jung et al. (10) reported that two phytoplasmas should be grouped under the same species-level taxa if they have 16S rRNA gene sequence identity more than $97.5 \%$. The sequence homology in the present SCGS-causing phytoplasma is more than $99 \%$, and their homology with SCWL and BGWL is from 98 to $99 \%$. Therefore, it can be concluded that SCGS, SCWL, SGS, and BGWL belong to the same species-level taxa. The phylogenetic tree computed by the neighbor-joining method also revealed that all the phytoplasmas causing SCGS, SCWL, SGS, and BGWL form a stable phylogenetic subcluster, as judged by branch length and bootstrap values of $100 \%$ in the RYD $16 \mathrm{~S}$ group clusters. This indicated that these phytoplasmas are closely related and share a common ancestor. However, Fox et al. (9) reported that $16 \mathrm{~S}$ rRNA gene sequence homology may not be able to distinguish between recently diverged species. Smart et al. (23) also reported that genetic variation of $16 \mathrm{~S}$ rRNA gene sequences within a given group of phytoplasmas is difficult because of the high level of sequence conservation. Instead, sequence diversity of 16S-23S rRNA SR could be used to identify different strains of phytoplasmas classified within the same group. In the present paper, we report that $16 \mathrm{~S}-23 \mathrm{~S}$ rRNA SR sequence diversity could be used to distinguish recently diverged strains within a given group of phytoplasmas in a sugarcane crop. In most of the phytoplasmas, the $16 \mathrm{~S}-23 \mathrm{~S}$ rRNA SR sequences were identical, regardless of the phenotypic symptoms of the infected plants. Similarly, closely related phytoplasmas have been reported to induce different phenotypic symptoms, and different types of phytoplasmas to induce similar symptoms $(7,8,14,15)$.

In the present study, we found that two phytoplasmas, BV2 (DQ380342) and VD7 (DQ380343), showed similar phenotypic symptoms, but the sequence similarity with that of other phytoplasmas from the present study was only 79 and $84 \%$, respectively. Figure 3 also shows that BV2 (DQ380342) and VD7 (DQ380343) diverged to the separate subcluster in the cluster shared by NS1 (DQ380336) and other SCGS and SCWL isolates. The long branching of BV2 (DQ380342) and VD7 (DQ380343) supports recent divergence from the SCGS phytoplasma.

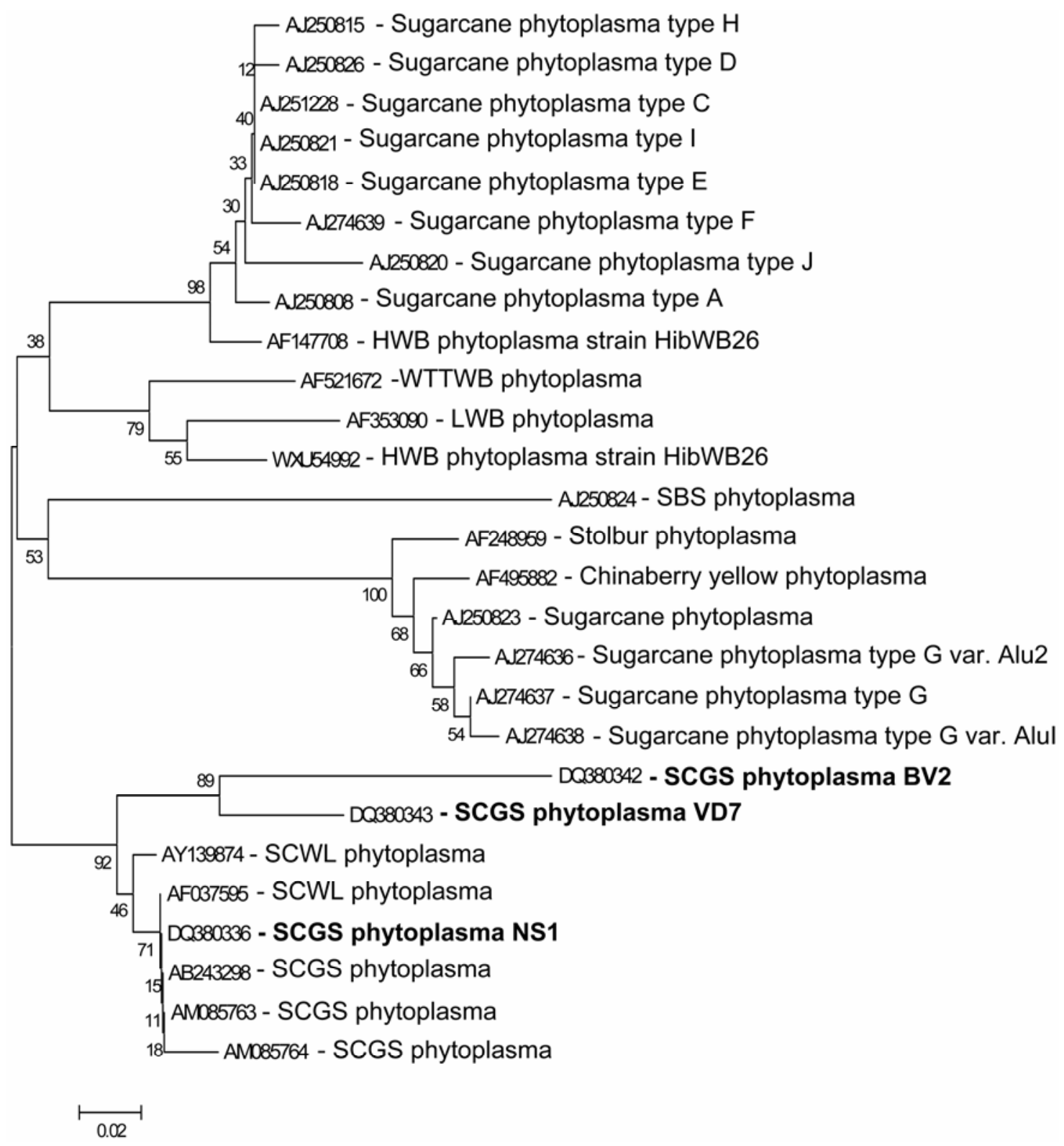

Fig. 4. Phylogenetic tree constructed by neighbor-joining method, comparing the 16S-23S rRNA spacer region (SR) sequences of sugarcane phytoplasma with those of other related phytoplasmas from GenBank. 16S-23S rRNA SR gene sequences of phytoplasmas determined in this study are in bold. Bar represents phylogenetic distance of $2 \%$. Numbers on branches are confidence percentage obtained from 1,000 bootstrap replicates. 
From the present investigation, it is clear that there is one phytoplasma (NS1) that is more prevalently associated with SCGS disease in India, but there are two other phytoplasmas, which have diverged from the existing NS1 in their 16S-23S rRNA SR sequence. This study adds to our knowledge of the diversity of phytoplasma infecting sugarcane crop in India. We also report two new SCGS phytoplasmas never reported earlier.

It may also be concluded that although $16 \mathrm{~S}$ rRNA sequence can be used routinely to distinguish and establish relationships between genera and well-resolved phytoplasma species, very recently diverged species may not be recognized by this criterion. On the other hand, the $16 \mathrm{~S}-23 \mathrm{~S}$ rRNA SR provides greater genetic variation than 16S rRNA sequence; hence, it is more suitable for distinguishing newly evolved strains within a given species.

\section{ACKNOWLEDGMENTS}

This work was financially supported by the Department of Biotechnology, Government of India, and internal grants of ICGEB, New Delhi, India and VSI, Pune, India to VSR and YSN.

\section{LITERATURE CITED}

1. Ahrens, U., and Seemüller, E. 1992. Detection of DNA of plant pathogenic mycoplasmalike organisms by a polymerase chain reaction that amplifies a sequence of the 16S rRNA gene. Phytopathology 82:828-832.

2. Altschul, S. F., Gish, W., Miller, W., Myers, E. W., and Lipman, D. J. 1990. Basic local alignment search tool. J Mol. Biol. 215:403410 .

3. Blanche, K. R., Tran-Nguyen, T. T., and Gibb, K. S. 2003. Detection, identification and significance of phytoplasmas in grasses in northern Australia. Plant Pathol. 52:505-512.

4. Chen, C. T. 1974. Sugarcane white leaf disease in Thailand and Taiwan. Sugarcane Pathol. Newsl. 11:12-23.

5. Chen, C. T., and Kusalwong, A. 2000. White leaf. Pages 231-236 in: A Guide to Sugarcane Diseases. P. Rott, R. A. Bailey, J. C. Comstock, B. J. Croft, and A. S. Saumtally, eds. CIRAD ISSCT, France.

6. Chona, B. L., Capoo, S. P., Varma, P. M., and Seth, M. L. 1960. Grassy shoot disease of sug- arcane. Indian Phytopathol. 13:37-47.

7. Davis, R. E., and Sinclair, W. A. 1998. Phytoplasma identity and disease etiology. Phytopathology 88:1372-1376.

8. Firrao, G., Gibb, K., and Streten, C. 2005. Short taxonomic guide to the genus 'Candidatus phytoplasma'. J. Plant Pathol. 87:249-263.

9. Fox, G. E., Wisotzkey, J. D., and Jurtshuk, P. 1992. How close is close: $16 \mathrm{~S}$ rRNA sequence identity may not be sufficient to guarantee species identity. Int. J. Syst. Bacteriol. 42:166170.

10. Jung, H. Y., Sawayanagi, T., Kakizawa, S., Nishigawa, H., Miyata, S., Oshima, K., Ugaki, M., Lee, J. T., Hibi, T., and Namba S. 2002. 'Candidatus phytoplasma castaneae', a novel phytoplasma taxon associated with chestnut witches' broom disease. Int. J. Syst. Evol. Microbiol. 52:1543-1549.

11. Jung, H. Y., Sawayanagi, T., Wongkaew, P., Kakizawa, S., Nishigawa, H., Wei, W., Oshima, K., Miyata, S., Ugaki, M., Hibi, T., and Namba, S. 2003. 'Candidatus Phytoplasma oryzae', a novel phytoplasma taxon associated with rice yellow dwarf disease. Int. J. Syst. Evol. Microbiol. 53:1925-1929.

12. Kumar, S., Tamura, K., and Nei, M. 2004. MEGA3: Integrated software for Molecular Evolutionary Genetics Analysis and sequence alignment. Briefings Bioinfo. 5:150-163.

13. Lee, I. M., Davis, R. E., Chen, T. A., Chiykowski, L. N., Fletcher, J., Hiruki, C., and Schaff, D. A. 1992. A genotype-based system for identification and classification of mycoplasmalike organisms (MLOs) in the aster yellows MLO strain cluster. Phytopathology 82:977-986.

14. Lee, I. M., Davis, R. E., and GundersenRindal, D. E. 2000. Phytoplasma: Phytopathogenic mollicutes. Annu. Rev. Microbiol. 54:221-255.

15. Martini, M., Vibio, M., Sfalanga, A., and Bertacini, A. 1998. Molecular and ecological diversity of phytoplasmas belonging to the elm yellows group in Italy towards their tentative epidemiology. Program Abstr., Int. Org. Mycoplasmol. Conf., 12th, Sydney, Aust., p. 130.

16. Namba, S., Kato, S., Iwanami, S., Oyaizu, H., Shiozawa, H., and Tsuchizaki, T. 1993. Detection and differentiation of plant pathogenic mycoplasmalike organisms using polymerase chain reaction. Phytopathology 83:786-791.

17. Purcell, A. H. 1985. The ecology of bacterial and mycoplasma plant diseases spread by leafhoppers and planthoppers. Pages 351-380 in: The Leafhoppers and Planthoppers. L. R. Nault and J. G. Rodriguez, eds. John Wiley \& Sons, New York.
18. Rishi, N., and Chen, C. T. 1989. Grassy shoot and white leaf disease. Pages 289-300 in: Diseases of Sugarcane. B. C. Ricaus and B. T. Egan, eds. Elsevier Science Publisher, Amsterdam.

19. Sambrook, J., and Russell, D. W., eds. 2001. Molecular Cloning. A Laboratory Manual, 3rd ed. Cold Spring Harbor Laboratory, Cold Spring Harbor, NY

20. Sarosh, M., Kishan-Singh, S. R., and Singh, K. 1986. Anatomical studies on sugarcane affected with grassy shoot disease. Indian Phytopathol. 39:499-502.

21. Sinclair, W. A., and Griffiths, H. M. 2000. Variation in aggressiveness of ash yellows phytoplasmas. Plant Dis. 84:282-288.

22. Singh, V., Baitha, A., and Sinha, O. K. 2002. Transmission of grassy shoot disease of sugarcane by a leafhopper (Deltocephalus vulgaris) Indian J. Sugar. Technol. 17:60-63.

23. Smart, C. D., Schneider, B., Blomquist, C., Guerra, L. J., Harrison, N. A., Ahrens, U., Lorenz, K. H., Seemüller, E., and Kirkpatrick, B. C. 1996. Identification of phytoplasma strainspecific PCR primers obtained from $16 \mathrm{~S} / 23 \mathrm{~S}$ rRNA spacer sequences. Appl. Environ. Microbiol. 62:2988-2993.

24. Srivastava, S., Singh, V., Gupta, P. S., Sinha, O. K., and Baitha, A. 2006. Nested PCR assay for detection of sugarcane grassy shoot phytoplasma in the leafhopper vector Deltocephalus vulgaris: A first report. Plant Pathol. 22:25-28.

25. Taylor, R. A. J. 1985. Migratory behaviour in Auchenorrhyncha. Pages 259-288 in: The Leafhoppers and Planthoppers. L. R. Nault and J. G. Rodriguez, eds. John Wiley \& Sons, New York.

26. Viswanathan, R. 2000. Grassy shoot. Pages 215-220 in: A Guide to Sugarcane Diseases. P Rott, R. A. Bailey, J. C. Comstock, B. J. Croft, and A. S. Saumtally, eds. CIRAD ISSCT, France.

27. Wongkaew, P. 1999. Sugarcane white leaf disease and control strategies. Thailand Research Fund. T \& R Celeca, Bangkok.

28. Wongkaew, P., and Fletcher, J. 2004. Sugarcane white leaf phytoplasma in tissue culture: Long-term maintenance, transmission, and oxytetracycline remission. Plant Cell Rep. 23:426-434.

29. Wongkaew, P., Hanboonsong, Y., Sirithorn, P., Choosai, C., Boonkrong, S., Tinnangwattana, T., Kitchareonpanya, R., and Damak, S. 1997. Differentiation of phytoplasmas associated with sugarcane and graminaceous weed white leaf disease and sugarcane grassy shoot disease by RFLP and sequencing. Theor. Appl. Genet. 95:660-663. 